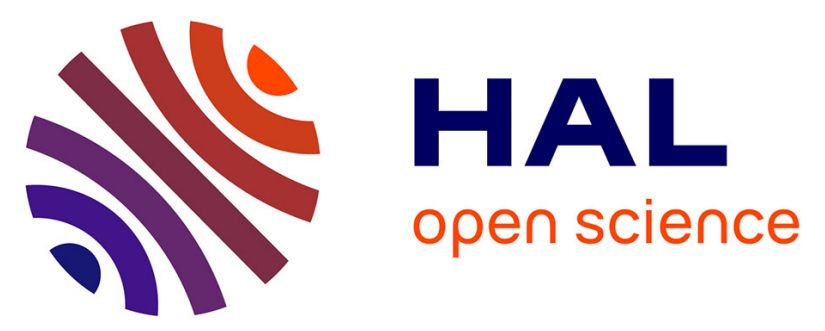

\title{
A pathway design framework for sectoral deep decarbonization: the case of passenger transportation
}

Julien Lefevre, Yann Briand, Steve Pye, Jordi Tovilla, Francis Li, Ken Oshiro, Henri Waisman, Jean-Michel Cayla, Runsen Zhang

\section{- To cite this version:}

Julien Lefevre, Yann Briand, Steve Pye, Jordi Tovilla, Francis Li, et al.. A pathway design framework for sectoral deep decarbonization: the case of passenger transportation. Climate Policy, 2021, 21 (1), pp.Pages 93-106. 10.1080/14693062.2020.1804817 . hal-02919192

\section{HAL Id: hal-02919192 \\ https://hal.science/hal-02919192}

Submitted on 24 Aug 2020

HAL is a multi-disciplinary open access archive for the deposit and dissemination of scientific research documents, whether they are published or not. The documents may come from teaching and research institutions in France or abroad, or from public or private research centers.
L'archive ouverte pluridisciplinaire HAL, est destinée au dépôt et à la diffusion de documents scientifiques de niveau recherche, publiés ou non, émanant des établissements d'enseignement et de recherche français ou étrangers, des laboratoires publics ou privés. 


\title{
A pathway design framework for sectoral deep decarbonization: the case of passenger transportation
}

\author{
Julien Lefèvre ${ }^{\mathrm{a} 1}$, Yann Briand ${ }^{\mathrm{b}}$, Steve Pye ${ }^{\mathrm{c}}$, Jordi Tovilla ${ }^{\mathrm{d}}$, Francis Li $^{\mathrm{c}}$, Ken Oshiro ${ }^{\mathrm{e}}$, \\ Henri Waisman ${ }^{\mathrm{b}}$, Jean-Michel Cayla ${ }^{\mathrm{f}}$ and Runsen Zhang $^{\mathrm{g}}$
}

\begin{abstract}
${ }^{a}$ CIRED, AgroParisTech, CIRAD, CNRS, EHESS, Ecole des Ponts ParisTech, Université de ParisSaclay, Nogent-sur-Marne, France; ${ }^{b}$ Institut du Développement Durable et des Relations Internationales, IDDRI, Sciences Po, Paris, France; 'UCL Energy Institute, London, UK; ${ }^{\mathrm{d}}$ Tempus Analítica A. C., Mexico City, Mexico; ${ }^{\mathrm{e}}$ Department of Environmental Engineering, Kyoto University, Kyoto, Japan; ${ }_{\mathrm{f}}^{\mathrm{f}}$ Electricité de France, EDF, Paris, France.; ${ }^{\mathrm{g} H i r o s h i m a ~ U n i v e r s i t y, ~ H i r o s h i m a, ~ J a p a n ~}$
\end{abstract}

\begin{abstract}
The transport sector represents $25 \%$ of global $\mathrm{CO}_{2}$ emissions, and large-scale emission reductions are needed in this sector to meet the objectives of the Paris Agreement. Long term low-greenhouse gas emissions development strategies are key enabling instruments to reconcile near-to-medium term action with long term objectives. While a range of options exist to decarbonise the passenger transport sector, the detailed sequencing of actions and resulting transformations over time remain largely unexplained in policy debates. Scenarios from transport-energy modelling provide useful insights about technological strategies but often overlook other key drivers of transportation futures, including social, organisational and spatial determinants of mobility, and are not easily usable to inform policy discussions. In this paper, we introduce a new framework to design and compare long term national decarbonization pathways for passenger transportation. This framework is based on an iterative method combining detailed qualitative storylines, full scenario quantification and standardised dashboard reporting, adapted from the general Deep Decarbonization Pathways (DDP) framework. For illustration, the method is applied by four national research teams in Japan, the UK, Mexico and France, to derive country-specific decarbonization pathways. The results across countries show that: i) strong action is needed across all types of options to reach deep decarbonization, notably demand-side solutions; ii) deep decarbonization is compatible with other policy priorities such as satisfying mobility needs at affordable costs; and iii) strategies should be tailored to mobility purpose, local contexts and national circumstances. The framework can be adapted to other sectors and should be further developed in the context of future policy processes.
\end{abstract}

\footnotetext{
${ }^{1}$ Julien Lefèvre; jlefevre@centre-cired.fr; CIRED, AgroParisTech, CIRAD, CNRS, EHESS, Ecole des Ponts ParisTech, Université de Paris-Saclay, Campus du Jardin Tropical, 45 bis, avenue de la Belle Gabrielle, Nogent-sur-Marne 94736, France ; @jlnLefevre
} 


\section{Key Policy insights}

- Understanding deep decarbonization of the passenger transport sector requires a novel conceptual approach that articulates metrics across diverse dimensions (social, economic, energy, etc.) to increase policy relevance.

- We introduce a framework to design national decarbonization pathways for passenger transportation following this approach.

- Strong action across all pillars of decarbonization including demand-side solutions is needed to reach deep emissions reductions.

- Deep decarbonization is compatible with other policy priorities such as satisfying mobility needs at affordable costs.

- Strategies should be tailored to mobility purposes, local contexts and national circumstances.

Keywords: passenger transport, decarbonization, policy, scenarios, pathways

\section{Introduction}

Reaching the "well-below $2{ }^{\circ} \mathrm{C}$ " objective of the Paris Agreement (PA) requires that global $\mathrm{CO}_{2}$ emissions fall to net zero around the middle of this century (IPCC, 2018). With the transport sector currently representing approximately $25 \%$ of total energyrelated $\mathrm{CO}_{2}$ emissions ${ }^{2}$, deep decarbonization of this sector will be critical to meeting the PA goals. Existing median $1.5^{\circ} \mathrm{C}$ scenarios project that global $\mathrm{CO}_{2}$ emissions from the transport sector are approximately halved by 2050 (relative to 2010) (IPCC, 2018). Other scenarios show deeper reductions of emissions from this sector (Grubler et al., 2018; IEA, 2017). However, the ambition for the transport sector pledged by countries under the Nationally Determined Contributions (NDCs) by 2025-2030 remains limited. While $60 \%$ of those NDCs include mitigation measures specific to the transport sector, less than $50 \%$ include more than one specific action, and only $10 \%$ put forward an explicit emission reduction target (Gota et al., 2015; ITF/OECD, 2018).

2. $60 \%$ of which is linked to passenger transportation (FIT, 2019) 
"Long term [national] low GHG emission development strategies" are key enabling instruments under the Paris Agreement (Article 4.19) aimed at informing the NDC process and increasing ambition, by reconciling medium term action with long term objectives (Waisman et al., 2019). Such country-driven strategies should be designed at the economy-wide level to provide a systemic perspective (Bataille et al., 2016), while providing as much information as possible about the needed sectoral transformations. For passenger transport, as mobility access will increase in the future (FIT, 2019), deep decarbonization will require a mix of options in all countries, including the rapid diffusion of efficient low carbon vehicles and decarbonised fuels, modal shift towards low carbon modes like public transport and non-motorised transport (cycling and walking), and changes to urban systems design and use to reduce mobility needs. However, the way these options could be implemented and their sequencing over time remain largely unexplained in policy debates (Creutzig et al., 2015). 'Backcasting' pathways from a desired future towards present conditions is a useful approach to explore these questions, as it allows identification of the underlying drivers and enabling conditions for the transformations needed, and the required policy packages to address inertia, lock-ins and innovation (Waisman et al., 2019).

Drivers that need to be considered in these pathways include individual behaviours, lifestyles, societal and spatial organisation, infrastructures, and technological change. In particular, a greater understanding of the social dynamics underlying mobility of passengers is needed to identify demand-side solutions complementary to technologybased options (Creutzig, 2016). In addition, different communities of stakeholders ranging from individual consumers to urban planners and car industries - will provide differing visions, in both aim and coverage, about low carbon passenger transport futures.

To maximise policy impact and develop successful decarbonization strategies, a structured space for dialogue to consider these visions is needed (Baumann and White, 2015), based on a common comparison framework around internally consistent backcasted pathways. This framework should be based both on qualitative or semiquantitative language understandable by all stakeholders, and on comparable quantitative scenarios. While combined qualitative-quantitative participatory methods have been used to study transportation futures (Varho and Tapio, 2013; Venturini et al., 2019), a structured comparison framework informing all the main system 
transformations and public questions in the context of deep decarbonization is still lacking, as well as an analytical approach to structure and ensure a transparent policy debate.

Building on the economy-wide Deep Decarbonization Pathways (DDPs) approach (Bataille et al., 2016; Waisman et al., 2019), this paper aims to bridge this gap, by introducing a policy-focused comparison framework to design national deep decarbonization pathways for passenger transportation. The framework, which can be generalised to other sectors, is applied to four countries for illustrative purpose - Japan, the UK, Mexico and France - to build and compare country-specific pathways, with explicit consideration of demand-side mitigation drivers alongside non-climate policy goals. The rest of this paper is structured as follows: section 2 reviews the methodological challenges for policy-relevant DDPs in passenger transportation, section 3 introduces the new framework to design national DDPs; section 4 presents the illustrative results of the four country case studies and cross-cutting findings, and section 5 discusses the findings and presents policy conclusions.

\section{Methodological challenges for policy-relevant passenger transport decarbonization pathways}

There exists a rich literature on national decarbonization scenarios for the transport sector. (Gota et al., 2018) review 218 recently published decarbonization scenarios from 81 countries covering government roadmaps and studies (Department of Environmental Affairs, 2015; GIZ, 2017; Swedish Government, 2017; Transport for London, 2017), climate and energy modelling studies (Mittal et al., 2016; Shafiei et al., 2017), and bottom-up mitigation potential analyses (Figueroa et al., 2013; Hong et al., 2016; Staff, 2017). The review highlights that existing quantitative estimates mostly derive from integrated assessment models (IAMs) or energy-economy models with transport modules or transport-energy models such as described in (Pietzcker et al., 2014; Yeh et al., 2017). Using the Avoid-Shift-Improve (ASI) paradigm (Bongardt et al., 2013), these scenarios are able to provide insights on a range of low carbon transportation futures, resulting from the interplay between i) avoiding mobility needs and transport trips, ii) shifting to low carbon transport modes and fuels and iii) improving efficiency of 
transport services and energy efficiency of vehicles (Edelenbosch et al., 2017; Girod et al., 2013b) ${ }^{3}$.

However, most scenarios derived from these models focus on specific solution domains. The narratives used in the analyses are primarily focused on technological transformations and their underlying drivers, with models typically representing this technology-orientated change (Creutzig, 2016). Future mobility demand is often projected at the aggregated level and simply correlated to GDP in most cases, ignoring key drivers related to social practice, spatial organisation, and infrastructure change. With an emphasis on the supply-side technological solution domain, options for reduced mobility demand and modal shift see limited contribution to decarbonization (Edelenbosch et al., 2017). Consequently, the decarbonization potential at the global level could be underestimated by $20-50 \%$ (Creutzig, 2016) ${ }^{4}$. Only a limited number of modelling studies have attempted to explore the impact of changing demand-side drivers on decarbonization potential (Anable et al., 2012; Brand et al., 2018; Girod et al., 2013a).

In addition, the policy relevance of existing modelled scenarios may be limited for several reasons. Although energy models already play a crucial role for policy-making (Strachan et al., 2016), challenges remain in using them to support stakeholder participation, and they are often perceived as non-transparent "black boxes". Their quantitative nature also makes it difficult to directly reflect broad qualitative narratives. Finally, they are resource-intensive tools with well-known lack of flexibility that poses constraints to the integration of alternative visions and to engagement with stakeholders.

To address the above challenges, combined qualitative-quantitative participatory methods have been developed (Venturini et al., 2019), where scenarios build on the complementarity between qualitative narratives or storylines, and quantification of the pathways. Narratives, as coherent stories of the future, allow the collective creative process of investigating contrasted futures driven by alternative combinations of drivers and policies and identifying causal linkages and interdependencies (Banister and

3. For instance (Edelenbosch et al., 2017) decompose mitigation in transport scenarios through the standard four indicators inspired by the ASI framework: population, activity per capita, modal shares, energy intensity per mode and fuel mix.

4. More generally, demand-side aspects of mitigation have been insufficiently addressed in all sectors so far with energy models and remain a key research challenge (Creutzig et al., 2018). 
Hickman, 2013; Soria-Lara and Banister, 2018, 2017). Quantification of the narratives, including the physical, economic and social characteristics of pathways, allows description of the dynamics underpinning changing transport futures. Quantification can be based on numerical models (Fortes et al., 2015; Garb et al., 2008; Robertson, 2016) or other quantitative techniques (Varho and Tapio, 2013).

Although integrating qualitative and quantitative methods can be a challenging task (Fortes et al., 2015), a general approach is to identify the driving forces or drivers of future pathways and translate them into quantitative parameters to use in models. For example, (Venturini et al., 2019) considers the full range of drivers, including demandside, to explore the future of transportation in Denmark - macroeconomy, demography, technology but also urban planning, behaviours (e.g. lifestyle changes regarding tourism, work flexibility, sharing economy) and policies - and translate them into parameters for use in the TIMES-DK energy model. Such combined qualitativequantitative approaches can support participatory processes and help bridge the "implementation gap" between research and action (Banister and Hickman, 2013). These processes include the participatory building of narratives through various techniques, such as consultations and/or Delphi surveys (Kok et al., 2011; Nowack et al., 2011; Tuominen et al., 2014), and some iteration between qualitative and quantitative components. In practice, model runs can be shared and discussed among stakeholders to revise the narratives and the related drivers (Venturini et al., 2019), although such iterations and collective quantitative comparisons are limited in most existing studies.

Our review of the literature suggests that no combined qualitative-quantitative approach has been developed to fully explore future passenger transportation pathways that explicitly recognise underlying demand-side and technological drivers together, under transitions towards deep decarbonization. Developing such a framework - with enhanced features for iterative development and quantitative assessment of scenarios would allow for both a more comprehensive assessment of the options and enhanced engagement with stakeholders. This, in turn, would enable the co-construction of pathways, solutions and policies that meet both climate and non-climate objectives (e.g. access to affordable mobility, improvement to quality of life). 


\section{A pathway design framework for passenger transport deep decarbonization}

To help bridge the identified research gaps, we present a new combined qualitativequantitative framework to design and compare consistent national deep decarbonization pathways. This framework builds on the general DDP approach developed in (Waisman et al., 2019) and is based on three components: i) qualitative storylines considering the full set of decarbonization drivers, ii) full quantification of pathways and iii) a core quantitative dashboard for iterative backcasting and comparison. These elements of the framework are illustrated in Figure 1.

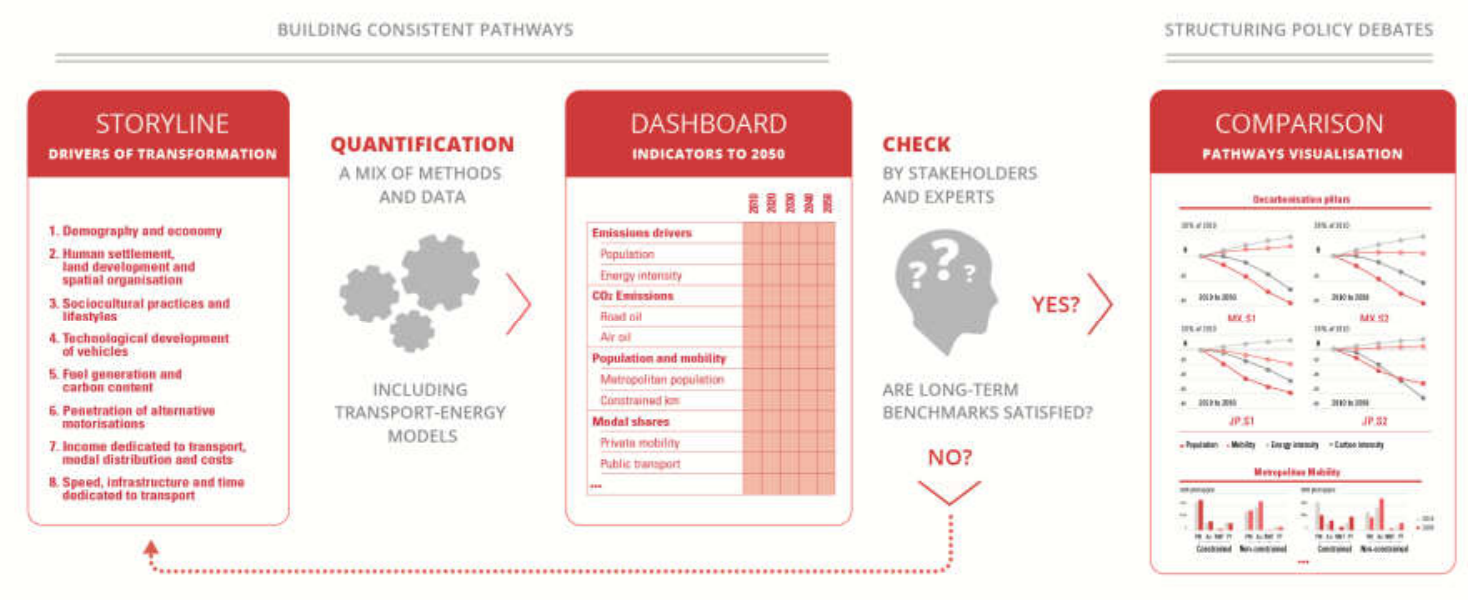

REVISED STORYLINE ASSUMPTIONS

Figure 1. Sectoral DDP framework adapted to the passenger transport sector. An iterative process for building consistent pathways: storylines are fully quantified, summarized in the dashboard and checked against long-term benchmarks before possible revision. The graphic pathway visualisation further facilitates pathway comparison to contribute to policy debates. Credit: Ivan Pharabod

\subsection{Building qualitative storylines considering the full set of decarbonization} drivers

The first component of the approach shown in Figure 1 derives from existing methods to build qualitative storylines but adapted to the context of deep decarbonization. Storylines for decarbonised transportation futures must address how the ASI pillars are implemented and interact with each other. Examples of the typical questions used to build the storylines are: what role could a reduction in future mobility demand play? Would this reduction be the result of demographic trends, urban reorganisation, or lifestyle changes? Would a reduction in the energy intensity of mobility be due to more efficient private vehicles, a modal shift to public transport modes, or a higher occupancy rate of vehicles? 
Critical to this approach is that storylines go deeper in exploring the complex underlying drivers that cut across the decarbonization pillars. For instance, a change of modal structure at the aggregated level is not a driver per se but the consequence of local transformations related to infrastructure, the speed and cost of modes, accessibility, etc. Thus, storylines should also answer detailed questions such as, for which household situations, in which geographical context, for which trip purpose, for which distances, and at which speed and cost, would people shift from private car to public transport? This way a richer discussion of the policy-relevant conditions, option levers, uncertainties and potential transformations over time is enabled. Decarbonization storylines should also connect to other non-climate national objectives, e.g. to what extent mobility needs can be reduced while fulfilling objectives linked to access to activities and improvements to quality of life.

Influencing drivers fall under eight main categories (as shown in the far left box of Figure 1):

1) Demography and economy;

2) Human settlement, land development and spatial organisation;

3) Sociocultural practices and lifestyles;

4) Technological development of vehicles;

5) Fuel generation and carbon content;

6) Penetration of alternative engine types and fuels;

7) Income dedicated to transport, modal distribution and costs;

8) Speed, infrastructure and time dedicated to transport;

For instance, in the "Human settlement, land development and spatial organisation" category (2), the storyline should describe: i) the split of future population in rural, suburban and urban areas; ii) the evolution of constrained (or essential) and nonconstrained (non-essential) mobility needs in the different areas according to urban planning policies; iii) the connection with changes in individual practices and lifestyles; and iv) the connection with changes of transport modes. The storyline thus provides a first detailed and consistent description of the interactions between drivers and their impacts towards deep decarbonization of transport.

\subsection{Deriving full quantified pathways}


The full quantification of the storylines cannot rely on a single energy model because many of the dimensions would fall outside the model boundary. Non-energy system dimensions include demographic profile, the geography of urban spaces, urban planning, consumer preferences and their impact on travel demand, etc. These are important elements of the analysis. Therefore, instead of using a particular model, we build on the logic of a comprehensive data template that includes variables across all dimensions and that can be informed from various sources to fully translate the storyline. This enables the choice of the best available modelling tools for scenario development. The storyline quantification then combines results of modelling runs with out-of-the box assessments and expert-based assumptions to give a measure of some elements in the pathways.

On the case studies presented in this paper, specific analysis of the determinants of mobility demand focused on trip purpose based on travel surveys, and demand by modes across different geographies. For instance specific calculations were performed in the French case to quantify the impacts of population ageing, remote activities and behavioral change on future mobility demand. The modal shifts projections in the UK scenarios build on a previous study based on a transport-energy model with endogenous mode choice (Pye and Daly, 2015). Establishing the links between the qualitative storyline drivers and quantitative implications is one of the more challenging aspects, often due to lack of available empirical data or evidence. The link is sometimes only indirect by means of appropriate proxies (e.g. urban policies towards more mixed and diversified land-use in suburban areas is connected to "constrained (or essential) kilometres travelled per capita in suburbs"). Energy models still retain a key role, with their primary application being to explore the transport supply side (fuel use, vehicle stock, investment requirements, emissions accounting).

Overall, the full quantitative information is collated in the data template designed to be self-consistent, thanks to a 'construction process' that involves many check points amongst indicators to ensure consistency between intermediate indicators (vehicle.km, passenger.km, energy consumption/passenger.km, $\mathrm{CO}_{2} /$ energy consumption, etc.). Crucially, the approach is flexible enough to allow for future sources of uncertainties to be easily tested by sensitivity analysis in a transparent manner (e.g. about how future changes in social practices will impact transport demand). 


\subsection{Using a standardised quantitative dashboard for iterative backcasting and comparison}

A key aspect of the method is to introduce a standardised quantitative dashboard that is populated based on the quantified pathways holding the relevant quantitative information that translate each storyline. In other words it provides a summary description of the pathways using policy-relevant indicators. The variables and metrics involved in the quantification of scenarios can differ across models and diverge from stakeholders' points of view, so a first issue is to align accounting measures and timeframes to get comparable results. Second, the dashboard should be able to inform the key questions posed by the different communities of stakeholders, given their priorities related to the transformation of the passenger transport sector. Based on the combined experience of country teams, key issues raised in these national contexts were identified to inform the design of a common dashboard. A limited number of quantitative indicators were selected and structured around six main topics: population and mobility; modal share; budget, time and distance; car stock and sales; energy; and emissions. Table 1 in the appendix shows examples of the types of questions raised and the related indicators. The dashboard, although concise, goes beyond the standard ASI decomposition to add policy-relevant details about system transformation. For example, individual mobility (passenger.km per capita) can be specified for different geographies, income or age groups, transport modes, etc. In this way, the evolution of 'constrained $\mathrm{km}$ travelled for people living in metropolitan areas' helps to characterise the future mobility practices related to essential activities in metropolitan areas, in relation to future social organisation and urban planning. Similarly, the 'disposable income dedicated to transport' (as a \% of disposable income) helps to understand the financial impacts on households of each pathway.

The dashboard is firstly a tool for a transparent dialogue between stakeholders. It allows the comparison of how different policy objectives are met under alternative pathways (e.g. emissions levels, satisfaction of mobility needs for different purposes, affordability of mobility), the framing of necessary policy interventions in quantitative terms, and for a discussion of the plausibility and relevance of the different transformations of social changes regarding mobility practices, technological evolution of the vehicle fleets, etc. Secondly, the dashboard feeds into an iterative process of stakeholder discussion to inform the construction of pathways, as shown in Figure 1. After being quantified and 
summarised in the dashboard, a storyline can be "checked" in quantitative terms regarding different criteria (consistency with policy objectives, plausibility of transformations, consistency with stakeholder's views and benchmarks, etc.). Gaps and inconsistencies identified by stakeholders and experts in the dashboard are useful to revisit the storylines and launch a second round of quantification. Finally, and critically for enabling shared practice, this common format summarises the main sectoral transformations and their related drivers in a common language allowing (with additional graphic visualisation, see Figure 1) for comparisons, benchmarking and learning across different country perspectives.

\section{Illustrative applications of the framework}

The framework developed in this paper has been applied by four research teams in Japan, the UK, Mexico and France to design two distinctive DDPs for each country, of the passenger transportation system evolution out to 2050. These exercises were carried out to explore the added value of the framework presented here. The method has not been applied yet in actual participatory processes - its ultimate goal - but the research teams sought to integrate various existing stakeholders' visions in building their pathways. Teams were free to define their scenarios according to the specificities of their national circumstances with the main constraint to develop two contrasting scenarios to reflect key uncertainties. A first insight of this bottom-up exercise is that the resulting scenarios share common features between countries with one scenario emphasizing demand-side drivers and solutions (DEM scenario), and a stronger technological focus in the other (TEC scenario). While storylines differ by country due to different visions of the future, the country scenarios for both the DEM and TEC types share common principles: DEM scenarios emphasize options linked to demand-side social and organisational change (lifestyle, land use planning, infrastructure and modal shift), whereas TEC scenarios emphasize technological solutions with limited consideration of change in mobility demand trends and the structure of the transport systems. A brief description of the eight country scenarios can be found in the appendix (Table 2), with full descriptions provided in individual country reports ${ }^{5}$. Finally, the 
standardised metrics collated in the eight dashboards ${ }^{6}$ make it possible to derive intercountry analysis and highlight both commonalities and country specific insights. The rest of this section provides some of the key results from these country-level exercises.

\subsection{Decarbonization potential and pillars}

A first important insight from the analysis is that all country scenarios demonstrate the potential to significantly reduce emissions by 2050 from passenger transport (from $50 \%$ to $-89 \%$ compared to the 2010 level, see Figure 2 ).

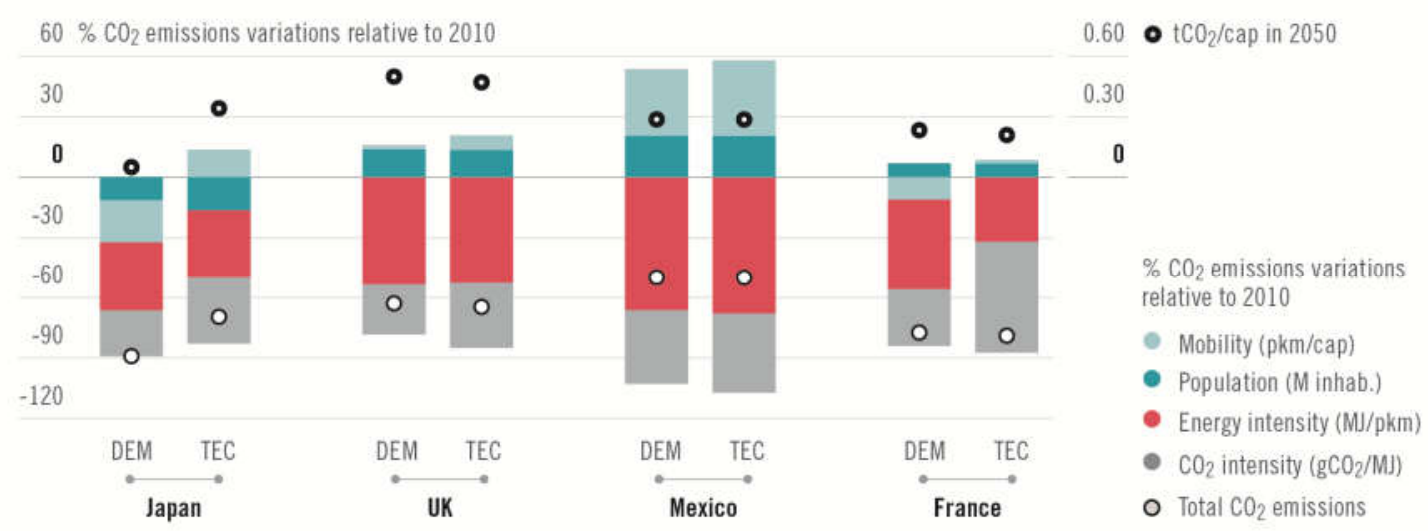

Figure 2. Decarbonization pillars and residual emissions/cap in 2050 in DEM and TEC scenarios across countries

Figure 2 also shows that emissions reductions lead to similar levels of residual emissions per capita in 2050 across countries $\left(0.27-0.38 \mathrm{tCO}_{2} /\right.$ cap) - except for the UK (around $0.50 \mathrm{tCO}_{2} / \mathrm{cap}$ ) because of the inclusion of sizable residual emissions from international aviation. Such levels of $\mathrm{CO}_{2}$ emissions per capita in 2050 extrapolated at the global level (around $3 \mathrm{GtCO}_{2}$ total emissions globally from passenger transportation) would be aligned with the $2{ }^{\circ} \mathrm{C}$ or even below $2{ }^{\circ} \mathrm{C}$ target in some cases (Rogelj and al., 2018). For these residual emissions, international aviation proves to be the sector for which supply side options are inadequate to move towards carbon neutrality ${ }^{7}$. In addition, it is evident that a diversity of options is needed to reach deep

6. The full dashboards and standardised graphs for the eight DDPs can be found in the Supplementary material.

7. Despite aircraft efficiency gains and increasing biofuel use, such measures are only sufficient to keep emissions at current levels due to rapid sectoral growth. Policies focused on demandside reductions are therefore crucial for this sector. 
decarbonization, illustrated by the implementation of the different decarbonization pillars across both scenario types.

Figure 2 shows the decomposition of total emission reductions in 2050 compared to 2010 across four decarbonization pillars following the $\mathrm{LMDI}^{8}$ decomposition method (Ang, 2005; Ang and Liu, 2001). The decrease in energy intensity of mobility is the largest pillar across most countries and scenarios (from 1.0-1.5 MJ/pkm in 2010 to 0.4$0.8 \mathrm{MJ} / \mathrm{pkm}$ in 2050 , a $44-61 \%$ decrease). It results not only from the increase of the energy efficiency of cars but also from the shift towards more energy efficient transport modes (e.g. rail is around five times more efficient than car transport) and changes in the provision of mobility services, such as through car sharing. The reduction in the $\mathrm{CO}_{2}$ intensity of energy is only the second largest driver in most scenarios (from 71-73 $\mathrm{gCO}_{2} / \mathrm{MJ}$ in 2010 to $40-48 \mathrm{gCO}_{2} / \mathrm{MJ}$ in 2050 , a $32-45 \%$ decrease). Specifically, DEM scenarios highlight a significant role for the reduction of mobility demand per capita compared to TEC scenarios, and relative to 2010 levels. In Japan in particular, larger emission reductions are estimated to be possible with additional consideration of demand-side measures. Future population and growth in mobility needs (as discussed below) are important drivers that differ significantly between countries, as shown by the opposite trends for Mexico and Japan.

\subsection{Mobility demands}

As highlighted in the description of the approach, a key strength is the production of demand-focused scenarios, to explore both underlying uncertainty in the future of mobility, but also a range of under-investigated mitigation levers for sector decarbonization. First of all, average mobility demand per capita increases for all countries in TEC scenarios, although at different rates (from $0.1 \% /$ year in France to 1.3\%/year in Mexico). Such increases are aligned with most existing model-based low carbon scenarios (Creutzig, 2016; Edelenbosch et al., 2017) and usually with forecasts produced at a country level ${ }^{9}$.

DEM scenarios make it possible to explore alternative mobility patterns that diverge from projected trends towards lower mobility levels. For all countries, average mobility

\footnotetext{
8. Log-Mean Divisia Index

9. For instance, mobility projection in the TEC scenario for the UK is aligned with the forecasts produced by the UK Department for Transport (DfT. Road traffic forecasts 2015)
} 
per capita is considerably lower in DEM scenarios than in TEC scenarios in 2050, although to differing degrees: it is only $6 \%$ lower in Mexico but $52 \%$ lower in Japan. Average mobility per capita reduces in absolute terms by 2050, relative to 2010 in Japan, France and the UK (excluding international aviation) by $40 \%, 13 \%$ and $19 \%$ respectively (see Figure 3). This compares to an absolute increase in the case of Mexico, which reflects convergence of mobility levels in 2050 to the average level of the three other countries in 2010 in the context of increases in income per capita.

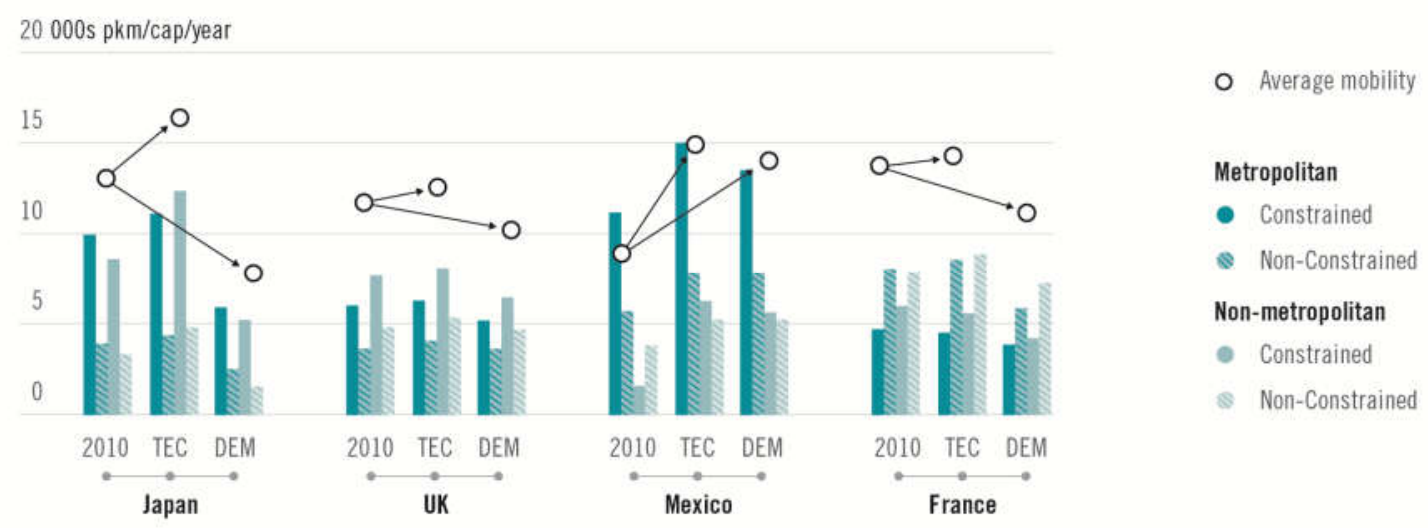

Figure 3. Average mobility demand per capita in 2010 and in DEM and TEC scenarios in 2050 in the four countries, and split by constrained and non-constrained mobility demand in metropolitan and non-metropolitan areas.

To explore the changes in mobility demands and the underlying drivers in more details, the dashboard provides additional granularity of mobility patterns in terms of geography (metropolitan vs non-metropolitan areas) and purpose of mobility (constrained essential - vs non-constrained activities) as is shown in Figure 3. For all countries in DEM scenarios, mobility per capita is lower for all purposes and in both types of areas in 2050 either in absolute terms compared to 2010, or relative to the TEC scenario (for Mexico). Reduction of mobility is stronger for constrained purposes in general. These reductions happen via a range of mechanisms and underlying drivers. In all countries constrained mobility is reduced or managed through similar actionable drivers ${ }^{10}$ including societal shifts towards more remote activities (remote work, e-commerce,

10. As opposed to ageing, for instance, which is seen as another important driver of the reduction of average mobility demand but is not actionable and will not work in all scenarios 
etc.) and enhanced urban/land planning, towards higher density living areas with more mixed and diversified land-use ${ }^{11}$. The potential and conditions for these mechanisms are specific to countries and areas: for instance, in France, with already very dense city centres, the potential to increase the density of living areas is higher in suburbs than in metropolitan areas. In the UK, a key additional driver of reducing mobility demand is the increase of the share of the population living in metropolitan areas. In addition, Japan and France consider significant lifestyle changes, which lead to reducing nonconstrained mobility associated with leisure activities. This is treated as a general trend in Japan, and specific to long distance air and land transport-based mobility of the urban population in France.

\subsection{Modal shift}

DEM scenarios all show that, in addition to a future with lower mobility demand, there are also large opportunities for changes to modal structure (see Figure 4).
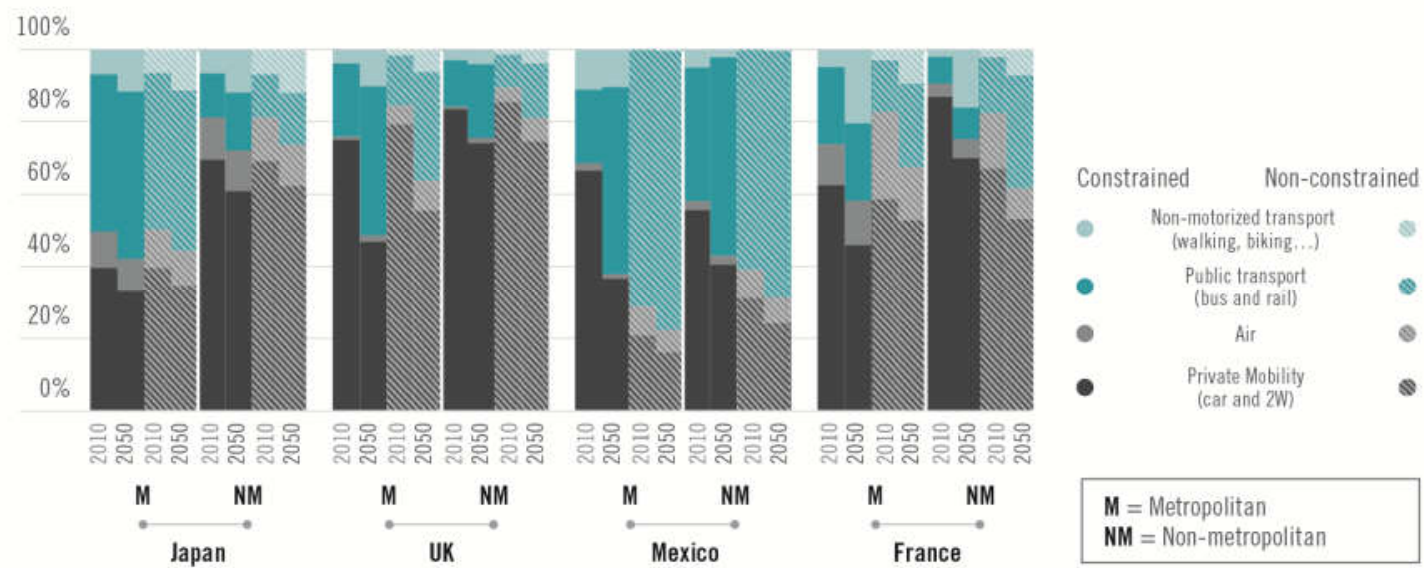

Figure 4. Shares of transport modes (public transport, non-motorised transport, air transport and private mobility) in DEM scenario in 2050 compared to 2010, by country, geographical area (metropolitan vs non-metropolitan), and type of mobility demand (constrained vs non-constrained)

In our scenarios, the largest changes to modal structure are observed for constrained demand, especially in metropolitan areas like in Mexico and the UK. For all countries, the shift is driven by a significant decrease in the share of constrained demand met by

11. Urban planning towards 'compactification' is seen as a key strategy to reduce transport emissions (Creutzig, 2016). 
cars (15-30\% reduction in France, the UK and Mexico in 2050 compared to 2010, see Figure 4).

However, modal shift strategies differ across countries: in Mexico and the UK, metropolitan populations can be more easily served by public transport systems as an alternative to cars for commuting, whereas in France, cars are mostly replaced by nonmotorised modes in both metropolitan and non-metropolitan areas. These specific modal shift strategies can be related to the country specific geographic contexts and urban planning approaches. In France, accelerating the 'compactification' of already dense living areas (in both metropolitan areas and suburbs) makes it possible to increase mobility met by non-motorised modes. Conversely in Mexico, large metropolitan areas with higher levels of constrained mobility (see Figure 4) favour reliance on longer distance public transportation. The UK develops non-motorised transport in cities but only as a complement to a structural shift towards public transportation. In addition, modal shift is significant for non-constrained mobility in France and the UK. In both countries, car travel for leisure purposes sees strong shifts towards bus, rail and nonmotorised modes. In France, domestic leisure-based air travel is also partly replaced by long distance bus and rail. Scenarios in Japan envisage more limited modal shifts, similar for all purposes and geographical areas, while the strongest driver is a decrease of individual mobility irrespective of the transport mode.

\subsection{Technology deployment}

While DEM scenarios highlight key measures for mobility reduction and modal shift, all scenarios rely on vehicle technology and fuel substitution to reach deep decarbonization, notably with the transition of the passenger car fleet from fossil liquids to electricity. Both the UK and Japan see almost full electrification of cars by 2050 , while France and Mexico see high penetration levels of electric vehicles. As a result, $40-50 \%$ of the car stock in 2030 consists of electric vehicles in Japan and the UK. This high electrification outlook is observed in both DEM and TEC scenarios, suggesting it is fundamental to whatever strategy is adopted (see Supplementary Material).

A necessary prerequisite for this deployment at scale is a carbon-free power generation sector, with an average carbon intensity of less than $20 \mathrm{gCO}_{2} / \mathrm{kWh}$. The scenario analysis also reflects on the infrastructure implications for large-scale electrification of cars, including charging infrastructure requirements and possible grid reinforcement, 
but also the potential benefits of battery storage services for the grid. On charging, for example, the analysis for France suggests about 3.4 to 4.8 million charging stations in 2030, and 6.3 to 9.6 million in 2050 under both scenarios.

While most countries deploy similar supply-side solutions mainly based on electric vehicles, the French case is notable for the higher level of bioenergy use ${ }^{12}$. Bioenergy under the form of liquid biofuels and biogas represents $43 \%$ of the total final energy consumed by passenger transportation in the TEC scenario in 2050. For other countries, resource-limited bioenergy-based fuels tend to be used in other sectors, where their carbon value is deemed higher. This shows the importance of using integrated modelling tools, to feed such insights into the dashboard. Some consumption of oilbased fuels remains in 2050 in most scenarios, especially for aviation.

\subsection{Convenience and cost}

Another key feature of the dashboard are the metrics relating to convenience and cost (e.g. travel time, transport budget, see Supplementary Material), which illustrate how the framework integrates other non-climate policy objectives. This feature is of particular importance for the French domestic debate, but also to some extent for the other countries. Over time, the cost share of travel reduces due to increasing income over time, counteracting increases resulting from investment in low carbon technologies and infrastructure. An important insight from the results is that the demand focused strategies can, in the main, lead to lower costs and time savings, in addition to shorter distances travelled. This is most evident in the France and Japan scenarios where the adoption of new technologies and behaviours, a more ambitious restructuring of cities to increase local supply of activities and to promote non-motorised local travel, as well as internal population dynamics, have a more profound impact in lowering future mobility demand, and the money and time spent on travel, than in other country cases. The Mexico analysis crucially underlines that, while this is the case on average, transport policy also needs to recognise that lower income households will struggle to afford adequate transport access if measures are not put in place to improve present underinvestment in public transport systems.

12. This reflects one of the visions debated in France in recent years, which could be challenged in the context of more constrained bioenergy resources and the faster improvement of EV's batteries. 


\section{Discussion and conclusions}

\subsection{A new approach to decarbonization analysis}

The goal of this paper is to introduce a structured framework to design and compare future pathways for passenger transportation at the country level, informing how to deliver different system transformations, in the context of deep decarbonization and other non-climate policy goals. The development and application of this framework highlights the importance of improving understanding of the underlying drivers of passenger mobility, and how these change over time. By incorporating the factors that will impact mobility trends going forward, whether they be uncertainties around social practice or opportunities for policy to shape urban design and alternative transport systems, a much richer picture of the challenges and opportunities emerges. The framework, which identifies underlying drivers of transport demand and supply and characterises the nature of actions to be adopted, can help map out possible direct (e.g. emissions standards for new vehicles, investment in infrastructures) or indirect (e.g. opportunities for changes in urban design) policy interventions. The framework itself is not used for policy design per se, but rather identifies potential areas for intervention, beyond transport fuels and technologies.

From the application of the framework to four national contexts, a key insight is the role that demand-side actions can play alongside supply-side focused technological options to achieve deep decarbonization. The illustrative scenarios developed show significant potential for reduced mobility demand and modal shift to reduce energy consumption and emissions, which is typically underexplored. Another important insight is that decarbonization pathways can be designed to support the delivery of other policy priorities and development goals. As shown with our scenarios, decarbonization can be consistent with satisfying mobility needs for the whole population across all countries, while demand-side actions can help alleviate the time and monetary burden of constrained mobility for households. Finally, different strategies see stronger potential in different country contexts, according to policy and development goals, demographic characteristics, spatial organisation, and socio-cultural practices.

\subsection{A framework to structure stakeholders and policy debates}

The main objectives of the framework are to structure policy debates and to facilitate the co-production of pathways across stakeholders groups. Challenges remain for its 
practical implementation in actual stakeholder processes. Key conditions include the appropriation of the approach by stakeholders (with training involved) and adequate consultation processes with regular meetings to discuss iterations of the scenarios. Furthermore the proposed framework is about organizing principles to enable the development of a shared definition of deep decarbonization strategies; it is not a static or complete method but rather a platform for further development, where new indicators that support emerging transport policy questions and priorities can be included (e.g. air pollution impacts). It also provides a basic structure for governments to inform national public debates on comprehensive transport decarbonization strategies, and to support planning and target-setting exercises, such as the NDCs. It could also be used by regional administrations e.g. cities, corporations or NGOs to design their own scenarios and contribute to the policy debate, or for international collaboration projects.

A key benefit of the approach is its transparency, which allows for a wide range of stakeholders to scrutinize assumptions and test alternatives. This is particularly important for policy makers who may be wary of venturing too far from traditional techno-economic scenario analysis, particularly where the evidence base for doing so is limited. In addition, the policy insights that can be derived from the analysis are valuable indicators of the direction of changes needed. However, an additional layer of policy analysis could be envisioned to complement the pathway design framework, in order to connect more explicitly the pathways to the policies and the specific policy instruments consistent with meeting the goals.

Finally, while passenger transportation has been the focus of this paper, the same approach could be adapted to explore deep decarbonization pathways in other sectors, with work ongoing to develop an approach for freight transportation (Briand et al., 2019). All sectors have a broader set of underlying drivers, which could usefully feature in storylines to be further analyzed to explore a wider range of mitigation options. For example, in industry this might relate to changing patterns in consumer preferences for products, new construction practices that impact demand for steel and cement, and changes in product lifetime impacting on replacement rates of different goods. 


\section{Acknowledgements}

This work was supported by the Agence Nationale de la Recherche of the French government through the Investissements d'avenir [ANR-10-LABX-14-01] programme.

\section{Disclosure statement}

No potential conflict of interest was reported by the authors.

\section{References}

Anable, J., Brand, C., Tran, M., Eyre, N., 2012. Modelling transport energy demand: A sociotechnical approach. Energy Policy 41, 125-138.

Ang, B.W., 2005. The LMDI approach to decomposition analysis: a practical guide. Energy Policy 33, 867-871.

Ang, B.W., Liu, F.L., 2001. A new energy decomposition method: perfect in decomposition and consistent in aggregation. Energy 26, 537-548.

Banister, D., Hickman, R., 2013. Transport futures: Thinking the unthinkable. Transp. Policy 29, 283-293.

Bataille, C., Waisman, H., Colombier, M., Segafredo, L., Williams, J., Jotzo, F., 2016. The need for national deep decarbonization pathways for effective climate policy. Clim. Policy 16, S7-S26.

Baumann, C., White, S., 2015. Collaborative stakeholder dialogue: a catalyst for better transport policy choices. Int. J. Sustain. Transp. 9, 30-38.

Bongardt, D., Creutzig, F., Hüging, H., Sakamoto, K., Bakker, S., Gota, S., Böhler-Baedeker, S., 2013. Low-carbon land transport: policy handbook. Routledge.

Brand, C., Anable, J., Morton, C., 2018. Lifestyle, efficiency and limits: modelling transport energy and emissions using a socio-technical approach. Energy Effic. 1-21.

Creutzig, F., 2016. Evolving narratives of low-carbon futures in transportation. Transp. Rev. 36, 341-360.

Creutzig, F., Jochem, P., Edelenbosch, O.Y., Mattauch, L., van Vuuren, D.P., McCollum, D., Minx, J., 2015. Transport: A roadblock to climate change mitigation? Science 350, 911912.

Creutzig, F., Roy, J., Lamb, W.F., Azevedo, I.M., de Bruin, W.B., Dalkmann, H., Edelenbosch, O.Y., Geels, F.W., Grubler, A., Hepburn, C., 2018. Towards demand-side solutions for mitigating climate change. Nat. Clim. Change 8, 268.

Department of Environmental Affairs, 2015. The South Africa 2050 Calculator.

Edelenbosch, O.Y., McCollum, D.L., van Vuuren, D.P., Bertram, C., Carrara, S., Daly, H., Fujimori, S., Kitous, A., Kyle, P., Broin, E.ó., 2017. Decomposing passenger transport futures: Comparing results of global integrated assessment models. Transp. Res. Part Transp. Environ. 55, 281-293.

Figueroa, M.J., Fulton, L., Tiwari, G., 2013. Avoiding, transforming, transitioning: pathways to sustainable low carbon passenger transport in developing countries. Curr. Opin. Environ. Sustain. 5, 184-190.

FIT, 2019. ITF Transport Outlook 2019.

Fortes, P., Alvarenga, A., Seixas, J., Rodrigues, S., 2015. Long-term energy scenarios: Bridging the gap between socio-economic storylines and energy modeling. Technol. Forecast. Soc. Change 91, 161-178.

Garb, Y., Pulver, S., VanDeveer, S.D., 2008. Scenarios in society, society in scenarios: toward a social scientific analysis of storyline-driven environmental modeling. Environ. Res. Lett. 3, 045015 . 
Girod, B., van Vuuren, D.P., de Vries, B., 2013a. Influence of travel behavior on global CO2 emissions. Transp. Res. Part Policy Pract. 50, 183-197.

Girod, B., van Vuuren, D.P., Grahn, M., Kitous, A., Kim, S.H., Kyle, P., 2013b. Climate impact of transportation A model comparison. Clim. Change 118, 595-608.

GIZ, 2017. Sectoral implementation of Nationally Determined Contributions (NDCs): transport.

Gota, S., Huizenga, C., Peet, K., \& Kaar, G. (2015). Intended Nationally-Determined Contributions (INDCs) offer opportunities for ambitious action on transport and climate change. Partnership on Sustainable Low Carbon Transport.

Gota, S., Huizenga, C., Peet, K., Medimorec, N., Bakker, S., 2018. Decarbonising transport to achieve Paris Agreement targets. Energy Effic. 1-24.

Grubler, A., Wilson, C., Bento, N., Boza-Kiss, B., Krey, V., McCollum, D.L., Rao, N.D., Riahi, K., Rogelj, J., Stercke, S., 2018. A low energy demand scenario for meeting the $1.5 \mathrm{C}$ target and sustainable development goals without negative emission technologies. Nat. Energy 3, 515.

Hong, S., Chung, Y., Kim, J., Chun, D., 2016. Analysis on the level of contribution to the national greenhouse gas reduction target in Korean transportation sector using LEAP model. Renew. Sustain. Energy Rev. 60, 549-559.

IEA, 2017. Energy Technology Perspectives.

IPCC, 2018. Summary for Policymakers. In: Global Warming of $1.5^{\circ} \mathrm{C}$. An IPCC Special Report on the impacts of global warming of $1.5^{\circ} \mathrm{C}$ above pre-industrial levels and related global greenhouse gas emission pathways, in the context of strengthening the global response to the threat of climate change, sustainable development, and efforts to eradicate poverty.

ITF/OECD, 2018. Transport CO2 and the Paris Climate Agreement: Reviewing the Impact of Nationally Determined Contributions.

Kok, K., van Vliet, M., Bärlund, I., Dubel, A., Sendzimir, J., 2011. Combining participative backcasting and exploratory scenario development: experiences from the SCENES project. Technol. Forecast. Soc. Change 78, 835-851.

Mittal, S., Dai, H., Shukla, P.R., 2016. Low carbon urban transport scenarios for China and India: A comparative assessment. Transp. Res. Part Transp. Environ. 44, 266-276.

Nowack, M., Endrikat, J., Guenther, E., 2011. Review of Delphi-based scenario studies: quality and design considerations. Technol. Forecast. Soc. Change 78, 1603-1615.

Pietzcker, R.C., Longden, T., Chen, W., Fu, S., Kriegler, E., Kyle, P., Luderer, G., 2014. Long-term transport energy demand and climate policy: Alternative visions on transport decarbonization in energy-economy models. Energy 64, 95-108.

Pye, S., Daly, H., 2015. Modelling sustainable urban travel in a whole systems energy model. Appl. Energy 159, 97-107.

Robertson, S., 2016. A longitudinal quantitative-qualitative systems approach to the study of transitions toward a low carbon society. J. Clean. Prod. 128, 221-233.

Rogelj, J., al., 2018. Mitigation pathways compatible with $1.5^{\circ} \mathrm{C}$ in the context of sustainable development. In: Global warming of $1.5^{\circ} \mathrm{C}$. An IPCC Special Report on the impacts of global warming of $1.5^{\circ} \mathrm{C}$ above pre-industrial levels and related global greenhouse gas emission pathways, in the context of strengthening the global response to the threat of climate change, sustainable development, and efforts to eradicate poverty.

Shafiei, E., Davidsdottir, B., Leaver, J., Stefansson, H., Asgeirsson, E.I., 2017. Energy, economic, and mitigation cost implications of transition toward a carbon-neutral transport sector: A simulation-based comparison between hydrogen and electricity. J. Clean. Prod. 141, 237-247.

Soria-Lara, J.A., Banister, D., 2018. Collaborative backcasting for transport policy scenario building. Futures 95, 11-21.

Soria-Lara, J.A., Banister, D., 2017. Participatory visioning in transport backcasting studies: Methodological lessons from Andalusia (Spain). J. Transp. Geogr. 58, 113-126. 
Staff, I.E.A., 2017. Energy Technology Perspectives 2017: Catalysing Energy Technology Transformations. OECD.

Strachan, N., Fais, B., Daly, H., 2016. Reinventing the energy modelling-policy interface. Nat. Energy 1, 16012. https://doi.org/10.1038/nenergy.2016.12

Swedish Government, 2017. The Climate Policy Framework.

Transport for London, 2017. Mayor's transport strategy: draft for public consultation.

Tuominen, A., Tapio, P., Varho, V., Järvi, T., Banister, D., 2014. Pluralistic backcasting: Integrating multiple visions with policy packages for transport climate policy. Futures $60,41-58$.

Varho, V., Tapio, P., 2013. Combining the qualitative and quantitative with the Q2 scenario technique-The case of transport and climate. Technol. Forecast. Soc. Change 80, 611630.

Venturini, G., Hansen, M., Andersen, P.D., 2019. Linking narratives and energy system modelling in transport scenarios: A participatory perspective from Denmark. Energy Res. Soc. Sci. 52, 204-220.

Waisman, H., Bataille, C., Winkler, H., Jotzo, F., Shukla, P., Colombier, M., Buira, D., Criqui, P., Fischedick, M., Kainuma, M., Rovere, E.L., Pye, S., Safonov, G., Siagian, U., Teng, F., Virdis, M.-R., Williams, J., Young, S., Anandarajah, G., Boer, R., Cho, Y., Denis-Ryan, A., Dhar, S., Gaeta, M., Gesteira, C., Haley, B., Hourcade, J.-C., Liu, Q., Lugovoy, O., Masui, T., Mathy, S., Oshiro, K., Parrado, R., Pathak, M., Potashnikov, V., Samadi, S., Sawyer, D., Spencer, T., Tovilla, J., Trollip, H., 2019. A pathway design framework for national low greenhouse gas emission development strategies. Nat. Clim. Change 9, 261. https://doi.org/10.1038/s41558-019-0442-8

Yeh, S., Mishra, G.S., Fulton, L., Kyle, P., McCollum, D.L., Miller, J., Cazzola, P., Teter, J., 2017. Detailed assessment of global transport-energy models' structures and projections. Transp. Res. Part Transp. Environ. 55, 294-309. 


\section{Appendix}

Table 1. Examples of questions and related dashboard indicators

\begin{tabular}{|c|c|c|}
\hline $\begin{array}{l}\text { Questions used to inform } \\
\text { indicator choice }\end{array}$ & Indicators & Units \\
\hline $\begin{array}{l}\text { How will mobility patterns and } \\
\text { social activities be organised in } \\
\text { the different geographies? }\end{array}$ & $\begin{array}{l}\text { Constrained } \mathrm{km} \text { travelled for people living in } \\
\text { metropolitan areas } \\
\text { Non-constrained km travelled for people } \\
\text { living in metropolitan areas } \\
\text { Constrained km travelled for people living in } \\
\text { metropolitan areas } \\
\text { Non-constrained km travelled for people } \\
\text { living in metropolitan areas }\end{array}$ & $\mathrm{pkm} / \mathrm{cap} /$ year \\
\hline $\begin{array}{l}\text { What will be the role of public } \\
\text { transport and non-motorised } \\
\text { modes for constrained trips in } \\
\text { non-metropolitan areas? }\end{array}$ & $\begin{array}{l}\text { Public transport }-\mathrm{km} \text { travelled } \\
\text { Non-motorised transport }-\mathrm{km} \text { travelled } \\
\text { for constrained activities for people living in } \\
\text { non-metropolitan areas }\end{array}$ & $\mathrm{pkm} / \mathrm{cap} /$ year \\
\hline $\begin{array}{l}\text { Will the transition be socially } \\
\text { acceptable in non-metropolitan } \\
\text { areas? }\end{array}$ & $\begin{array}{l}\text { Income dedicated to transport due to } \\
\text { constrained and non-constrained activities } \\
\text { in metropolitan and non-metropolitan }\end{array}$ & $\begin{array}{l}\% \text { of disposable } \\
\text { income }\end{array}$ \\
\hline $\begin{array}{l}\text { How will electric vehicles } \\
\text { develop? }\end{array}$ & $\begin{array}{l}\text { Annual sales of Battery Electric Vehicles and } \\
\text { Plug-Hybrid Electric Vehicle } \\
\text { Share in car stock }\end{array}$ & $\begin{array}{l}\text { units sold / year } \\
\% \text { of car stock }\end{array}$ \\
\hline $\begin{array}{l}\text { What will be the future dominant } \\
\text { energy carrier after oil? }\end{array}$ & $\begin{array}{l}\text { Final energy demand by fuel (electricity, oil, } \\
\text { gas, synthetic fuels, etc.) }\end{array}$ & EJ \\
\hline $\begin{array}{l}\text { How will the aggregated } \\
\text { emission drivers change? }\end{array}$ & $\begin{array}{l}\text { Variation in population, individual mobility } \\
\text { (pkm/cap), mobility energy intensity } \\
(\mathrm{MJ} / \mathrm{pkm}) \text {, carbon content of fuels }\left(\mathrm{gCO}_{2} / \mathrm{MJ}\right)\end{array}$ & $\%$ change vs 2010 \\
\hline
\end{tabular}

Table 2. Brief descriptions of scenarios

\begin{tabular}{|c|c|c|c|c|}
\hline Country & $\begin{array}{l}\text { Scenario } \\
\text { type }\end{array}$ & $\begin{array}{l}\text { Scenario name } \\
\text { in country } \\
\text { study }\end{array}$ & Brief description & $\begin{array}{l}\mathrm{CO}_{2} \text { red. in } 2050 \\
\text { (rel. 2010) }\end{array}$ \\
\hline \multirow[t]{2}{*}{ Japan } & TEC & $\begin{array}{l}\text { AdvancedTech } \\
\text { (ADV) }\end{array}$ & $\begin{array}{l}\text { Focuses on the different technical } \\
\text { transformations in the transport and } \\
\text { energy sector, with restricted } \\
\text { consideration of societal demand-side } \\
\text { changes }\end{array}$ & $-69 \%$ \\
\hline & DEM & $\begin{array}{l}\text { Balanced } \\
\text { (BAL) }\end{array}$ & $\begin{array}{l}\text { Similar to ADV, but with an emphasis } \\
\text { on social changes, such as urban } \\
\text { structure, lifestyle and infrastructure }\end{array}$ & $-89 \%$ \\
\hline \multirow[t]{2}{*}{ UK } & TEC & $\begin{array}{l}\text { Freedom to } \\
\text { Roam (F2R) }\end{array}$ & $\begin{array}{l}\text { Supply side focused with patterns of } \\
\text { mobility demand similar to those seen } \\
\text { today. Rooted in the development of } \\
\text { new technologies (notably } \\
\text { autonomous vehicles) that strengthen } \\
\text { the motivation for car use by meeting } \\
\text { the demands of mobile lifestyles with } \\
\text { convenience. }\end{array}$ & $-65 \%$ \\
\hline & DEM & $\begin{array}{l}\text { No Place Like } \\
\text { Home (NPLH) }\end{array}$ & $\begin{array}{l}\text { Technology development shifts } \\
\text { mobility trends in another direction, } \\
\text { towards a sharing services model that } \\
\text { is also built around greater use of } \\
\text { other modes of transport, particularly } \\
\text { in metropolitan areas. }\end{array}$ & $-63 \%$ \\
\hline
\end{tabular}




\begin{tabular}{|l|l|l|l|l|}
\hline Mexico & TEC & $\begin{array}{l}\text { Technological } \\
\text { (TEC) }\end{array}$ & $\begin{array}{l}\text { Focuses on technological options, but } \\
\text { not demand reduction measures, as in } \\
\text { DEM. }\end{array}$ & $-50 \%$ \\
\cline { 2 - 5 } & DEM & $\begin{array}{l}\text { Demand } \\
\text { (DEM) }\end{array}$ & $\begin{array}{l}\text { Uses the full set of options to reduce } \\
\text { emissions, including demand } \\
\text { reduction from changes in urban } \\
\text { organisation and accessibility, } \\
\text { inequality reduction, and behaviour of } \\
\text { commuters. Same level of emissions } \\
\text { reduction than TEC is attained by less } \\
\text { stringent modal shifting, technology } \\
\text { evolution, and at a lower cost. }\end{array}$ & $-50 \%$ \\
\hline France & TEC & $\begin{array}{l}\text { Technology- } \\
\text { First (TECH-F) }\end{array}$ & $\begin{array}{l}\text { Considers the current mobility trends } \\
\text { and does not anticipate fundamental } \\
\text { changes in the mobility system. Thus, } \\
\text { it favours technological innovations } \\
\text { over systemic change and assumes } \\
\text { that low carbon technologies must } \\
\text { provide adequate solutions. }\end{array}$ & $-79 \%$ \\
\cline { 2 - 6 } & DEM & $\begin{array}{l}\text { Mobility-First } \\
\text { (MOB-F) }\end{array}$ & $\begin{array}{l}\text { Prioritises social, organisational and } \\
\text { technical transformations of the } \\
\text { mobility systems while subsequently } \\
\text { exploring the technological innovation } \\
\text { contribution to deep decarbonization. }\end{array}$ & $-77 \%$ \\
\hline
\end{tabular}


